\title{
Use of multivariate measures of disability in health surveys
}

\author{
J R H CHARLTON, ${ }^{1}$ D L PATRICK, ${ }^{2}$ AND H PEACH ${ }^{1}$
}

From the Department of Community Medicine, ${ }^{1}$ St Thomas's Hospital Medical School, London SE1 $7 E H$, and the Department of Social and Administration Medicine, ${ }^{2}$ University of North Carolina at Chapel Hill, USA

SUMMARY It has been claimed that the aggregation of information from several areas of life into a small set of global measures has certain advantages for describing disability. Global measures of disability were constructed from a modified version of an existing health survey instrument and the sickness impact profile (SIP) and their properties were tested. The disability items grouped satisfactorily into five global measures (physical, psychosocial, eating, communication, and work). All disability measures (global and original category scores) were poor predictors of service use by individuals but were related as expected to age and number of medical conditions. The global measures generally had lower standard errors and better repeatability. All scores exhibit J-shaped distributions for cross sectional data but the change in global measures over time was consistent with the normal distribution. Preferably, both global and category measures should be used for comparing changes over time between groups of individuals.

When there is no cure for a chronic disease attention must be focused on reducing the level of disability resulting from disease. The term disability has been the subject of a variety of interpretations. The World Health Organisation has proposed a taxonomy of disablement in terms of the three concepts, impairment, disability, and handicap. ${ }^{1}$ The term disability includes a large number of behavioural changes.

There are situations when an instrument that assesses separately the severity of many different types of disability would be preferred-for example, in monitoring the progress of a patient. Nevertheless, measures that combine information from several areas of life into a small set of more global indexes are claimed to have the following advantages:

(1) Disability can be summarised using a smaller number of scores, thus facilitating analysis and presentation.

(2) The repeatability of the scores is often increased.

(3) The use of scores in identifying disabled people is increased when the items are combined. Typically the individual score distributions obtained are highly skewed, and scores which apply to (say) fewer than $1 \%$ of the population would be of minimum use in testing hypotheses regarding the effect of changes in medical care on health status unless very large numbers of people are included in a study.

(4) A more global instrument often has greater precision when used to test hypotheses-for instance, greater disability leads to greater use of medical or social services.

(5) The use of a smaller set of measures creates a basis for reducing the size of the instrument.

This paper describes how global measures were developed for use in health surveys from an existing health status measure. It was tested on data collected during a longitudinal study of disabled people.

\section{Methods}

A validated questionnaire designed specifically to assess the severity of disability according to the WHO's broad definition does not exist. Hence existing health status instruments must be adapted for this purpose. The suitability of many of these health status instruments for particular purposes has been discussed. ${ }^{2-5}$ One such measure, the sickness impact profile developed in the United States, ${ }^{67}$ was chosen to assess the level of disability in a longitudinal health survey in England, since it could easily be adapted to measure disability as defined by 
WHO. Almost all of its 136 "yes/no" statements refer to restrictions of activity, and cover a broader spectrum of daily activities than are covered in other available instruments. The items are grouped into 12 sets of statements (categories) which assess the impact of sickness on different areas of daily life by means of 12 scores, each of which is a weighted sum of the statements that an individual considers applies to him or herself. Where necessary, items were rephrased to correspond to United Kingdom English usage, and the modified instrument is called the functional limitations profile (FLP). ${ }^{8}$

The health survey is based on a random sample of disabled people living in the community, stratified for age and sex to ensure equal numbers of men and women in the age groups 25-64 and 65-77. Altogether 839 adults, $81 \%$ of the disabled people who were identified by a postal screening of $10 \%$ of the households in the London Borough of Lambeth, an inner city area, were successfully interviewed. The screening process and the sampling and survey methodology have been described previously.9 ${ }^{90}$ Respondents who had only visual, hearing, or mental handicap were excluded from the sample interviewed. The severity of disability was assessed annually on three occasions as part of a longitudinal survey of their health and care.

\section{DEVELOPMENT OF GLOBAL MEASURES}

An overall functional limitations score was examined first to investigate how informative a single score would be. Correlations between category scores and overall score were calculated. Also the items recorded by respondents who had particular levels of disability were inspected.

The internal consistency of the items within individual categories was also examined, using nonmetric multidimensional scaling to show up the associations between items. ${ }^{11}$ The distances between pairs of points are directly related to the strength of the association between the items and the aim is to group "similar" items close together. The similarity between any two items was expressed as the number of times the items occurred together divided by the maximum number of times they could possibly have occurred together. This measure has the advantage that if the presence of a rarer but more severe item always implies the presence of a milder, more common item, a similarity coefficient of 1 will be obtained, and thus the items will be clustered close together. This would not necessarily be the case if a more symmetric coefficient-for example, a correlation coefficient-was used.

The original FLP categories were split only where there was clear grouping of the items into distinct clusters and the separate groupings made good sense.
The original 12 categories were tentatively divided into 21 sets of items. The extent to which these 21 summary measures were associated was explored for the entire disabled sample and for men and women separately in the following ways:

(1) Cross-sectionally at each of the three annual interview stages.

(2) As changes in scores between the first and third interview.

(3) For two random halves of the sample (both cross sectionally and as changes).

Two scores describing work disability ("not working due to ill health" and "work restrictions") were omitted from these analyses since previous results had indicated that work disability does not have the same importance for young and old, employed and not employed, and therefore should not be combined with other disability measures.

External criterion validity for a United Kingdom population was tested by regression analysis and graphical techniques. Each score was related to age, number of aids possessed, number of medical conditions (from a specified check list), contact with health services - that is, doctor or district nurse-in the previous 14 days, and self rating of health on a five point scale ranging from excellent to very poor. Disability was expected to increase as age, the number of aids possessed, and the number of medical conditions increased, and also to be higher for those with recent health service contact, those registered as disabled, and those with poorer self rating of health.

CONFIRMATION OF PROPERTIES CLAIMED FOR GLOBAL MEASURES

(1) A repeatability study was undertaken on a sample of 30 disabled patients attending a health clinic. Patients whom the doctors regarded as disabled and having conditions unlikely to be resolved within 48 hours were asked to complete a FLP questionnaire at the clinic and 48 hours later at home and post it in a reply paid envelope to the investigators. The agreement between scores on the two occasions was measured in terms of their mean difference. Item agreement was measured by the number of times an item was endorsed on both occasions expressed as a percentage of the number of times the item was endorsed on either occasion.

(2) To examine the ability of the global measures to identify disabled people, a table was prepared showing the proportion of the disabled sample identified on each of the individual category scores and the global measures.

(3) Category scores and global measures were compared for their abilities to discriminate between those who had and had not registered their disability with the local authority, and those who had and had 
Table 1 Correlations between FLP category scores in a sample of $83 \%$ disabled individuals

\begin{tabular}{|c|c|c|c|c|c|c|c|c|c|c|c|c|c|}
\hline & & $A P$ & $B C M P$ & $M P$ & $H M P$ & $\boldsymbol{R P P}$ & $S I P$ & $E M P$ & $A B P$ & $S R P$ & $E P$ & $C P$ & $W P$ \\
\hline Ambulation & AP & 1 & & & & & & & & & & & \\
\hline Bodycare and movement & BCMP & $0 \cdot 72$ & 1 & & & & & & & & & & \\
\hline Mobility & MP & 0.68 & 0.69 & 1 & & & & & & & & & \\
\hline Household management & HMP & 0.69 & 0.66 & 0.70 & 1 & & & & & & & & \\
\hline Recreation and pastimes & RPP & 0.58 & 0.50 & 0.57 & 0.66 & 1 & & & & & & & \\
\hline Social interaction & SIP & 0.47 & 0.50 & 0.58 & 0.54 & 0.63 & 1 & & & & & & \\
\hline Emotion & EMP & 0.34 & 0.40 & 0.38 & 0.35 & 0.41 & 0.61 & 1 & & & & & \\
\hline Alertness & ABP & 0.33 & 0.48 & 0.42 & $0 \cdot 41$ & 0.41 & 0.60 & 0.53 & 1 & & & & \\
\hline Sleep and rest & SRP & 0.51 & 0.49 & 0.59 & 0.58 & 0.57 & 0.53 & 0.42 & 0.47 & 1 & & & \\
\hline Eating & EP & $0 \cdot 28$ & 0.35 & 0.34 & 0.31 & $0 \cdot 30$ & 0.34 & 0.30 & $0 \cdot 30$ & $0 \cdot 34$ & 1 & & \\
\hline Communication & $\mathrm{CP}$ & $0 \cdot 29$ & 0.49 & 0.41 & 0.43 & 0.35 & 0.46 & 0.29 & 0.56 & $0 \cdot 30$ & $0 \cdot 19$ & 1 & \\
\hline Work & WP & $0 \cdot 16$ & 0.15 & $0 \cdot 18$ & $0 \cdot 18$ & $0 \cdot 22$ & 0.30 & $0 \cdot 25$ & 0.22 & $0 \cdot 18$ & $0 \cdot 16$ & $0 \cdot 20$ & 1 \\
\hline Overall FLP Score & FLP & 0.73 & 0.83 & $0 \cdot 80$ & $0 \cdot 80$ & 0.73 & 0.80 & 0.63 & 0.71 & 0.70 & 0.45 & 0.60 & $0 \cdot 37$ \\
\hline
\end{tabular}

not seen their doctor in the past 14 days. Logistic discriminant analysis was undertaken, using a $70 \%$ random subsample as the "learning set" (to develop the predictive equations) and calculating false positive and false negative rates for the remaining $30 \%$ of the sample. The analysis allowed for differences in age and sex of the respondents in addition to disability. The global summary measures developed by Bergner $e^{a} a^{6}$ were also tested on our data set.

(4) To test how well a shorter instrument might predict and thus substitute for the two global measures of disability, a short physical disability questionnaire with only 22 items was used in the final round of interviews (see appendix) and compared with the two global measures. Weights for the 22 item questionnaire were estimated by regression, based on a $65 \%$ random subsample of the disabled. The observed and predicted physical and psychosocial scores were compared for different subgroups of the remaining $35 \%$ of the respondents.

\section{Results}

Table 1 gives the correlations between category scores and an overall score. There was a strong association between category scores and overall score, although much clearer for some categories such as bodycare and movement than others such as work. Examination of the items endorsed for particular overall scores, however, showed that for the same score there was wide variation both in the number and type of items, so that there was no clear picture of what a particular score meant.

Multidimensional scaling results (MDS), confirmed by cluster analysis, suggested that the original categories could be split into 21 smaller, more coherent groups of items, 19 of which-that is, excluding two work scores-were then examined to see to what extent they could be combined into more global measures. The results of the cross sectional analyses for the individual years were very similar. Figure 1 shows how the 19 subcategories cluster together for the whole disabled sample based on data from the first interview. Most of the components of the original 12 categories are reasonably close together, an exception being body care, where the "incontinence" score is quite distinct from the other three scores (confinement, movement, self care). Figure 2 shows how the changes in scores between phases I and II are associated with each other. These groupings seem to be robust, since similar results were obtained from separate analyses for men and women and two random halves of the sample. Based on these results the disability items have finally been combined into five summary scores (two global measures and three residual category scores) for use in community surveys which form a minimum set for describing disability based on the FLP measure. Central measures are a global psychosocial scorethat is, emotion, alertness, sleep and rest, recreation, and social interaction-and a physical scorewalking, confinement, movement, self care, mobility, and household management. More peripheral measures are eating, communication, and work. Since incontinence and pain are not strictly speaking 


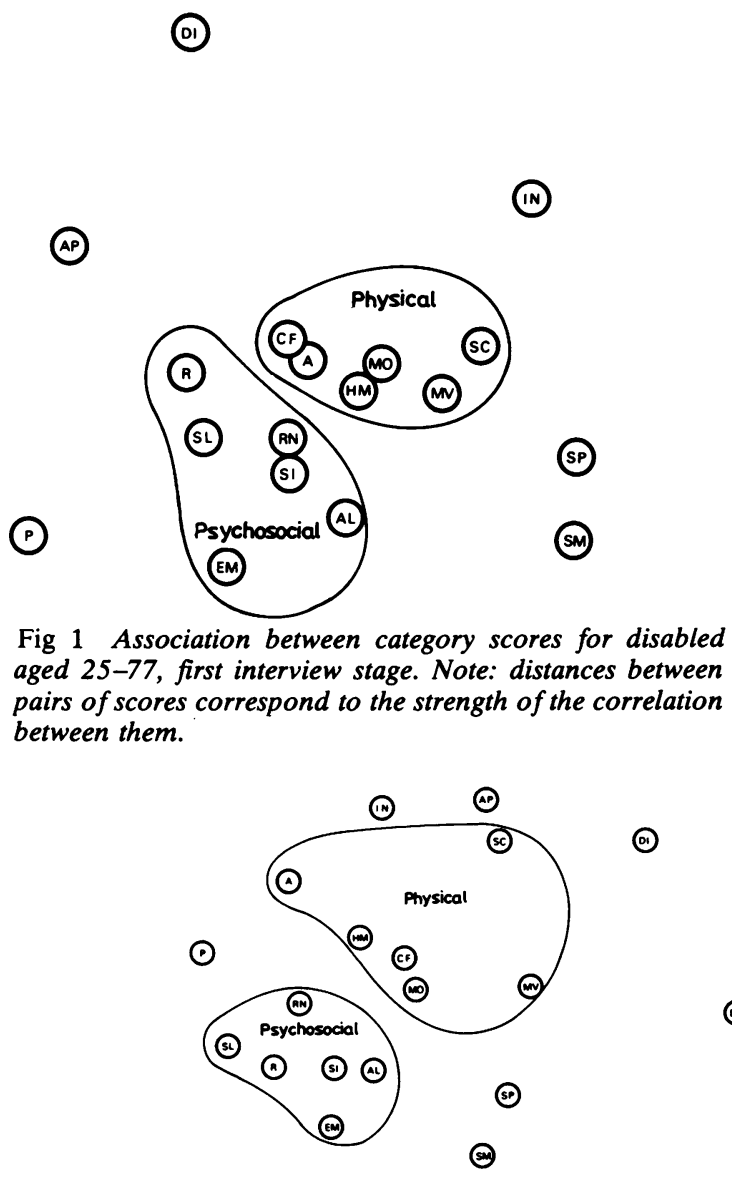

$\begin{array}{lll}\text { A } & \text { Ambulation } \\ \text { CF } & \text { Confinement } \\ \text { IN } & \text { Incontinence } \\ \text { MV } & \text { Movement } \\ \text { SC } & \text { Self care } \\ \text { MO } & \text { Mobility } \\ \text { HM } & \text { Household management } \\ \text { RN } & \text { Recreation and pastimes } \\ \text { SI } & \text { Social interaction } \\ \text { P } & \text { Pain } \\ \text { EM } & \text { Emotion } \\ \text { AL } & \text { Alertness } \\ \text { SL } & \text { Sleep } \\ \text { R } & \text { Rest } \\ \text { DI } & \text { Diet } \\ \text { AP } & \text { Appetite } \\ \text { EH } & \text { Edting help } \\ \text { SM } & \text { Sensory- motor communication } \\ \text { SP } & \text { Speech }\end{array}$

Fig 2 Association between changes in category scores between first and second interviews: disabled aged 25-77. Note: (as for fig 1).

disabilities, ${ }^{1}$ they have not been included in the multivariate measure of disability.

\section{VALIDITY OF RESULTANT MEASURES}

Figure 3 shows that the level of disability was higher for those registered as disabled with the local authority than for those who were not, on each category score and the global and summary measures. For self rating of health and number of medical conditions the level of disability also increased on all measures as the level of ill health increased, confirming external criterion validity, since all the disability measures are related to the other factors in the expected way.

REPEATABILITY OF SCORES OVER 48 HOURS

Table 2 gives the average change in each of the disability scores over a 48 hour period. Although changes in the global scores are generally smaller there are individual category scores which change less-for example, ambulation. The standard deviations of change in score (S) give an indication of the precision of the measurements. Based on this the global measures perform relatively better. The proportion of items that respondents endorsed on both occasions varied from $27 \%$ to $100 \%$ depending on the respondent, with a mean of $62.8 \%$ and standard deviation of $18 \cdot 8$. Repeatability of individual items (using data from all respondents) varied from $22 \%$ to $100 \%$. Although the sample was too small to estimate the reliability of any one item accurately, these results suggest that in general the repeatability of many individual items is low.

USE OF SCORES TO IDENTIFY DISABLED PEOPLE Table 3 compares the percentage of respondents 


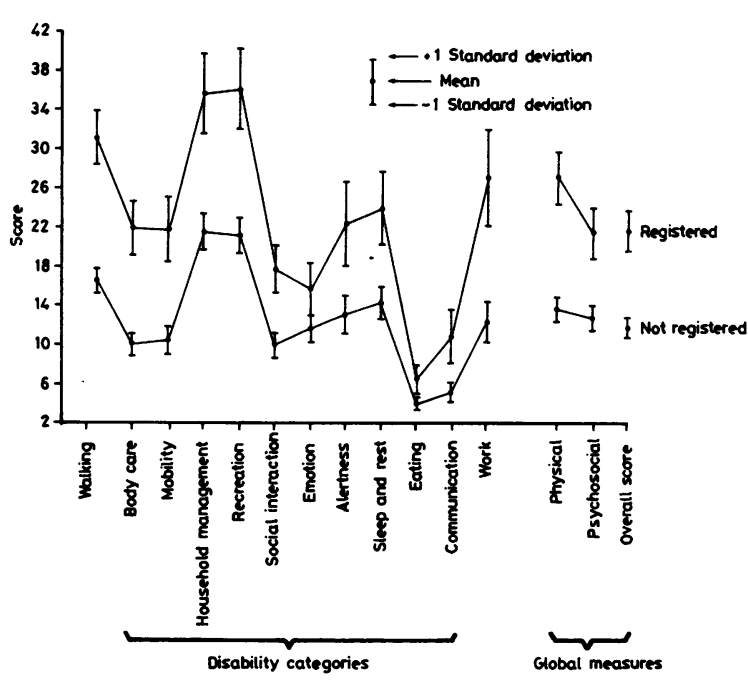

Fig 3 Mean levels of disability by registration of disability.

identified as disabled on each of the individual category scores and the physical and psychosocial global measures. Only a small proportion of respondents were identified as disabled by a single category score but not by the two global measure (0-33\% for physical, and $0-5 \cdot 6 \%$ for psychosocial). Conversely, a relatively high proportion of respondents who were identified by the global physical or psychosocial measures were missed by individual category scores. "Ambulation" and "household management" were areas in which a
Table 2 Average change* in disability scores over 48 hour period $(n=30)$

\begin{tabular}{|c|c|c|c|c|}
\hline Scores & Mean change & $\begin{array}{l}\text { Standard } \\
\text { deviation }\end{array}$ & $\begin{array}{l}\text { Mean initial } \\
\text { level }\end{array}$ & $\begin{array}{l}\text { Change as \% } \\
\text { initial level }\end{array}$ \\
\hline \multicolumn{5}{|l|}{ Category scores } \\
\hline Ambulation & -0.06 & $5 \cdot 34$ & $15 \cdot 53$ & $-1 \cdot 1$ \\
\hline Body care and movement & $-2 \cdot 58$ & $6 \cdot 42$ & $8 \cdot 45$ & $-40 \cdot 2$ \\
\hline Mobility & $2 \cdot 09$ & $6 \cdot 20$ & $10 \cdot 98$ & $19 \cdot 0$ \\
\hline Household managment & $2 \cdot 74$ & $11 \cdot 92$ & $21 \cdot 65$ & $12 \cdot 7$ \\
\hline Recreation and pastimes & $6 \cdot 51$ & $15 \cdot 04$ & $25 \cdot 53$ & $25 \cdot 5$ \\
\hline Social interaction & $2 \cdot 06$ & $7 \cdot 31$ & $12 \cdot 28$ & $16 \cdot 8$ \\
\hline Emotion & $2 \cdot 89$ & $10 \cdot 02$ & $12 \cdot 81$ & $22 \cdot 6$ \\
\hline Alertness & $-1 \cdot 19$ & $8 \cdot 52$ & $14 \cdot 70$ & $-8 \cdot 1$ \\
\hline Sleep and rest & 5.09 & $11 \cdot 20$ & $21 \cdot 40$ & $23 \cdot 8$ \\
\hline Eating & 0.04 & $2 \cdot 55$ & 3.89 & $1 \cdot 0$ \\
\hline Communication & 0.93 & $5 \cdot 80$ & $7 \cdot 23$ & $12 \cdot 9$ \\
\hline Work & $-0 \cdot 64$ & $3 \cdot 21$ & $1 \cdot 08$ & $-59 \cdot 3$ \\
\hline \multicolumn{5}{|l|}{ Global scores } \\
\hline Physical & $0 \cdot 20$ & $5 \cdot 37$ & $13 \cdot 06$ & $1 \cdot 5$ \\
\hline Psychosocial & $2 \cdot 40$ & $4 \cdot 93$ & $15 \cdot 65$ & $15 \cdot 3$ \\
\hline Overall FLP score & 0.63 & $3 \cdot 61$ & $11 \cdot 84$ & $5 \cdot 3$ \\
\hline
\end{tabular}

*First measurement minus second (positive difference indicates improvement).

relatively large number of people with "physical" disability were identified $(89 \%$ and $84 \%$ respectively).

Table 3 Relative abilities of global and category scores to identify disabled people $(n=839)$

\begin{tabular}{|c|c|c|c|c|c|c|c|}
\hline \multirow[t]{2}{*}{ Category } & \multirow[t]{2}{*}{$\begin{array}{l}\text { \% of sample disabled } \\
\text { in category }\end{array}$} & \multicolumn{3}{|c|}{$\begin{array}{l}\text { \% of total sample disabled in category but not } \\
\text { identified by global measures }\end{array}$} & \multicolumn{3}{|c|}{$\begin{array}{l}\text { \%o of total sample disabled according to global measur } \\
\text { but not disabled in individual categories }\end{array}$} \\
\hline & & Physical & Psychosocial & Both global measures & Physical & Psychosocial & Both global measures \\
\hline Eating & 37 & 3 & 3 & 2 & 48 & 46 & 53 \\
\hline Bodycare and movement & 65 & 1 & 4 & 0 & 18 & 20 & 24 \\
\hline Ambulation & 71 & 0 & 6 & 0 & 11 & 15 & 18 \\
\hline Mobility & 42 & 0 & 1 & 0 & 40 & 39 & 47 \\
\hline Work & 30 & 1 & $i$ & 1 & 54 & 53 & 59 \\
\hline Household management & 66 & 0 & 4 & 0 & 16 & 18 & 23 \\
\hline Recreation & 61 & 2 & 0 & 0 & 23 & 19 & 27 \\
\hline Sleep and rest & 54 & 1 & 0 & $\mathbf{0}$ & 29 & 26 & 34 \\
\hline Communication & 28 & 2 & 1 & 1 & 55 & 53 & 61 \\
\hline Alertness & 39 & 1 & 0 & 0 & 44 & 41 & 49 \\
\hline Emotion & 48 & 3 & 0 & 0 & 37 & 32 & 40 \\
\hline Social integration & 61 & 3 & 0 & $\mathbf{0}$ & 24 & 19 & 27 \\
\hline
\end{tabular}




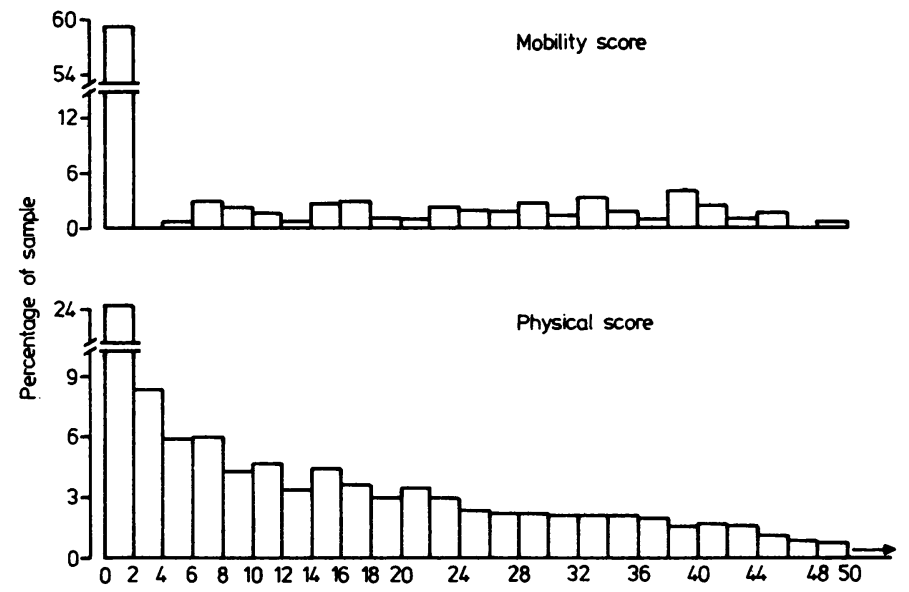

Fig 4 Distributions of mobility (categary) and physical (global) scores.

STATISTICAL ADVANTAGES OF GLOBAL MEASURES

For most of the individuals obtained in a community sample the category scores are the weighted sums of relatively few items, and so take a number of discrete values. Combining similar categories together into larger, global measures should improve statistical properties and, provided that they remain meaningful, simplify the description and analysis of disability in populations. Figure 4 shows the distributions of one of the category scores (mobility), and that of one of the global measures (physical disability). The global measure has a smoother distribution, although the shape of the distribution is still J-shaped. Figure 5 shows the distribution of change in scores for physical disability over a one year period.
The hypothesis that respondents with a greater level of disability were greater users of medical and social services.was tested. Disability level should be of use in discriminating between those who do and those who do not use services, although other factors are also important. Discriminant analyses were performed using logistic regression for different combinations of the global and category scores and table 4 shows the results for the test set (a random $30 \%$ of the sample). In every case the sets of disability scores were significantly related to use, but the false positive and false negative rates were high. The global measures in conjunction with "work", "communication," and "eating" worked about as well as the full set of 12 category measures, but such differences as exist were small. When the global measures developed by Bergner et $a l^{6}$ were tested

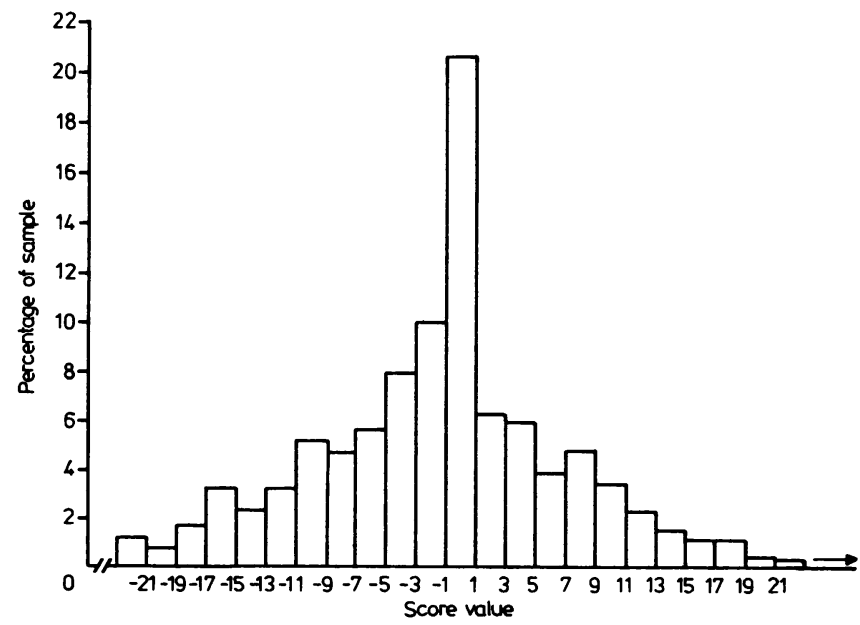

Fig 5 Change in physical score in one year. 
Table 4 Error rates in predicting service use from disability scores (\%)

\begin{tabular}{|c|c|c|c|c|c|c|c|}
\hline \multicolumn{2}{|c|}{ Model fitted } & \multicolumn{3}{|c|}{ Registration of disability } & \multicolumn{3}{|c|}{ Use of doctor in previous 14 days } \\
\hline & & $\begin{array}{l}\text { False } \\
\text { positives } \\
(n=176)\end{array}$ & $\begin{array}{l}\text { False } \\
\text { negatives } \\
(n=71)\end{array}$ & $\begin{array}{l}\text { Errors } \\
\text { overall } \\
(n=247)\end{array}$ & $\begin{array}{l}\text { False } \\
\text { positives } \\
(n=36)\end{array}$ & $\begin{array}{l}\text { False } \\
\text { negatives } \\
(n=111)\end{array}$ & $\begin{array}{l}\text { Errors } \\
\text { overall } \\
(n=247)\end{array}$ \\
\hline 1 & All 12 category scores & 3.4 & $74 \cdot 7$ & $23 \cdot 9$ & $19 \cdot 9$ & $64 \cdot 0$ & $40 \cdot 0$ \\
\hline 2 & $\begin{array}{l}\text { Physical, psychosocial, eating, work, } \\
\text { communication scores }\end{array}$ & $5 \cdot 1$ & $80 \cdot 2$ & $26 \cdot 7$ & $11 \cdot 8$ & $69 \cdot 4$ & $37 \cdot 7$ \\
\hline 3 & Overall FLP score & $2 \cdot 8$ & $81 \cdot 7$ & $25 \cdot 5$ & $9 \cdot 6$ & $67 \cdot 6$ & $35 \cdot 6$ \\
\hline 4 & $\begin{array}{l}\text { Seattle's physical, psychosocial, eating, } \\
\text { work, household management, } \\
\text { recreation, sleep, and rest scores }\end{array}$ & $4 \cdot 6$ & $76 \cdot 1$ & $25 \cdot 1$ & $14 \cdot 7$ & $66 \cdot 7$ & $38 \cdot 1$ \\
\hline
\end{tabular}

Table 5 Actual disability levels (FLP) and those predicted for population subgroups by a short 22 item questionnaire. (Test sample, $n=200$ )

\begin{tabular}{|c|c|c|c|c|c|c|c|c|c|}
\hline & \multicolumn{4}{|c|}{ Physical disability } & \multicolumn{4}{|c|}{ Psychosocial disability } & \multirow[t]{3}{*}{ No } \\
\hline & \multicolumn{2}{|l|}{ Actual } & \multicolumn{2}{|c|}{ Predicted } & \multicolumn{2}{|l|}{ Actual } & \multicolumn{2}{|c|}{ Predicted } & \\
\hline & $x$ & $(S E)$ & $x$ & $(S E)$ & $x$ & $(S E)$ & $x$ & $(S E)$ & \\
\hline $\begin{array}{l}\text { Age: } \\
25-44 \\
45-64 \\
65-77\end{array}$ & $\begin{array}{r}6 \cdot 41 \\
17 \cdot 63 \\
21 \cdot 48\end{array}$ & $\begin{array}{l}(1 \cdot 55) \\
(1 \cdot 84) \\
(1 \cdot 99)\end{array}$ & $\begin{array}{l}10 \cdot 43 \\
16 \cdot 14 \\
22 \cdot 56\end{array}$ & $\begin{array}{l}(1.06) \\
(1.46) \\
(1.65)\end{array}$ & $\begin{array}{r}7 \cdot 20 \\
15 \cdot 67 \\
14 \cdot 06\end{array}$ & $\begin{array}{l}(2.58) \\
(1.84) \\
(1.49)\end{array}$ & $\begin{array}{l}10 \cdot 17 \\
13 \cdot 65 \\
17 \cdot 70\end{array}$ & $\begin{array}{l}(0.93) \\
(1.05) \\
(1.26)\end{array}$ & $\begin{array}{l}32 \\
94 \\
74\end{array}$ \\
\hline $\begin{array}{l}\text { Sex: } \\
\text { Male } \\
\text { Female }\end{array}$ & $\begin{array}{l}15 \cdot 86 \\
18 \cdot 35\end{array}$ & $\begin{array}{l}(1.92) \\
(1.55)\end{array}$ & $\begin{array}{l}15 \cdot 80 \\
19 \cdot 07\end{array}$ & $\begin{array}{l}(1 \cdot 37) \\
(1 \cdot 36)\end{array}$ & $\begin{array}{l}11 \cdot 73 \\
15 \cdot 25\end{array}$ & $\begin{array}{l}(1 \cdot 57) \\
(1.56)\end{array}$ & $\begin{array}{l}13 \cdot 90 \\
15 \cdot 13\end{array}$ & $\begin{array}{l}(1.11) \\
(0.94)\end{array}$ & $\begin{array}{r}87 \\
113\end{array}$ \\
\hline $\begin{array}{l}\text { Main medical condition: } \\
\text { Arthritis } \\
\text { Other }\end{array}$ & $\begin{array}{l}22 \cdot 63 \\
16 \cdot 04\end{array}$ & $\begin{array}{l}(3.06) \\
(1.30)\end{array}$ & $\begin{array}{l}20 \cdot 57 \\
16 \cdot 92\end{array}$ & $\begin{array}{l}(2.68) \\
(1.03)\end{array}$ & $\begin{array}{l}13 \cdot 14 \\
13 \cdot 85\end{array}$ & $\begin{array}{l}(2.49) \\
(1.26)\end{array}$ & $\begin{array}{l}15 \cdot 75 \\
14 \cdot 33\end{array}$ & $\begin{array}{l}(1 \cdot 70) \\
(0 \cdot 79)\end{array}$ & $\begin{array}{r}37 \\
163\end{array}$ \\
\hline Correlation coefficients & & & 0.79 & & & & $=0.50$ & & \\
\hline
\end{tabular}

using the same data set very similar results were obtained.

\section{REDUCTION IN THE NUMBER OF QUESTIONNAIRE} ITEMS

The short 22 item questionnaire predicted both physical and psychosocial disability levels as measured by global scores reasonably well for subgroups of the population (table 5), with relatively little bias considering the magnitude of the standard errors. Physical disability is better predicted than psychosocial disability, as expected, owing to the physical nature of the short questionnaire items. The disability levels of individuals were less well predicted as evidenced by the correlation coefficients: 0.79 for physical and 0.50 for psychosocial disability (see appendix).

\section{Discussion}

The items were found to group into five sets (physical, psychosocial, eating, communication, and work) which were robust for men and women and two random subsamples of disabled people, both cross sectionally and over time. That disability items will split into physical and psychosocial dimensions has often been postulated. Bergner et al and Stewart et al also found that their health status indexes split into physical and psychosocial dimensions. ${ }^{612}$ Bergner's physical dimension consisted of ambulation, body care, and mobility, and her psychosocial dimension consisted of emotion, alertness, social interaction, and communication.

Several authors have attempted to form aggregate measures for describing disablement or health 
status. ${ }^{612}{ }^{14-16}$ The approach used by Bergner et al with the SIP, from which the FLP was developed, is based on the use of cluster analysis, while other authors (with different instruments) have used Guttman scaling, principal component analysis, or non data dependent methods. The use of Guttman scaling to develop measures from the 136 FLP items is inadvisable because many different types of dysfunction, some of similar severity, are included. In a perfect Guttman scale all the items are ordered according to severity, and if a more severe item applies so will all less severe items. We used nonmetric multidimensional scaling since it shows clusters more accurately in some situations whereas cluster analysis solutions often depend on the method and coefficient of similarity used. ${ }^{17}$ Nearest and furthest neighbour hierarchical cluster analyses were used as a further check on the solutions, and the items and groups of items which are similar in their pattern of occurrence have been grouped together. A full discussion of cluster analysis is given in Cluster Analyses by Everitt. ${ }^{17}$ Whereas other authors have only analysed such data cross sectionally we have also examined the associations between changes in scores over time, since we ultimately wished to use such global instruments longitudinally in studying the factors associated with changes in level of disability.

All 12 category scores and the global health status measures were equally bad predictors of service use. This lack of discrimination could be due to a lack of measurement sensitivity in the SIP, which uses several activities within the same question that may be performed at different levels of function. ${ }^{2}$ Disability, however, might not be expected to predict the use of the doctor accurately, since most respondents had visited the doctor to obtain a repeat prescription, and there are many other factors involved in doctor consultation. Registration of disability, too, is voluntary and somewhat arbitrary as it depends on the attitudes of the individual.

Some workers may still wish to use individual category scores or even individual items for particular studies. For example, distributing aids designed to circumvent specific physical disabilities will require knowledge of the prevalence of walking, bathing problems, etc. Evaluation of interventions may require a more precise outcome than a global measure of disability can provide-for instance, a randomised controlled trial designed to improve the mobility or ambulation category score. Individual items chosen from the FLP ( 24 of them) have been successfully used as a global score in a study of back pain. ${ }^{18}$ Where results concerning specific aspects of disability are not required global measures provide the most useful approach.
Although we have not shown all the advantages claimed for global health status measures, the five dimensions (physical, psychosocial, communication, eating, and work) provide a smaller number of scores with which to work and thus facilitate description. The instrument still comprises 136 statements but the five scores provide a basis on which to reduce this, as shown by the 22 item questionnaire of physical disability items. Some observations regarding scores can be made. The repeatability of certain items is low, and these should not be used individually. The repeatability of measures combining several items is higher, and the two global measures, especially physical disability, were found to have repeatability and standard errors which are generally better than those of the individual category scores, although some category scores were as good in this respect. Typically the distribution of scores comprising a collection of dysfunction items is J-shaped and account must be taken of this in the analysis. The distribution of changes in the global scores is approximately normal. All disability measures described here were poor predictors of individual service use, but performed rather better for groups of people. We would recommend that the best use of such measures is to compare changes over time for groups of individuals, for whom they perform reasonably well.

\section{References}

${ }^{1}$ World Health Organsiation. International classification of impairments, disabilities and handicaps. Geneva: WHO, 1980.

${ }^{2}$ Jette AM. Health status indicators: their utility in chronic disease evaluation research. J Chronic Dis 1980; 33: 567-79.

${ }^{3}$ Ware J, Brook RH, Davis AR, Lohr KN. Choosing measures of health status for individuals in general populations. Am J Public Health 1981; 71: 620-5.

${ }^{4}$ Brook RH, Ware J, Davies-Avery A, et al. Overview of adult health status measures fielded in Rond's health insurance study. Med Care 1979; 17: 1-131 (suppl).

${ }^{5} \mathrm{Krischer} \mathrm{JP.} \mathrm{Indexes} \mathrm{of} \mathrm{severity:} \mathrm{conceptual} \mathrm{development.}$ Health Serv Res 1979; 14: 56-66.

${ }^{6}$ Bergner M, Bobbitt RA, Carter WB, Gilson BS. The sickness impact profile: development and final revision of a health status measure. Med Care 1981; 19: 787805.

${ }^{7}$ Bergner M, Gilson BS. The sickness impact profile: the relevance of social science to medicine. In: Eisenberg L, Kleinman A, eds. The relevance of social science to medicine. Dordrecht: L Riedel and Co, 1981: 135-50.

${ }^{8}$ Patrick D. Standardisation of comparative health status measures: using scales developed in America in an English speaking country Health Survey Research Methods: 3rd biennial conference. Hyattsville, MD: US Department of Health and Human Services, 1981: 216-29. (Publication No (PHS) 81-326.

${ }^{\circ}$ Patrick D, Darby S, Green S, Horton G, Locker D, Wiggins R. Screening for disability in the inner city. $J$ Epidemiol Community Health 1981; 35: 65-70. 
${ }^{10}$ Patrick D, ed. Health and care of the physically disabled in Lambeth: Longitudinal interviews phases I and II. Vols I and II. London: Department of Community Medicine, St Thomas's Hospital Medical School, 1982.

${ }^{11}$ Kruskal J. Multidimensional scaling by optimising goodness of fit to a non-metric hypothesis. Psychometrika 1964; 29: 1-27.

${ }^{12}$ Stuart AL, Ware JE, Brook RH. Advances in the measurement of functional status: construction of aggregate indexes. Med Care 1980; 19: 473-88.

${ }^{13}$ Williams RGA, Johnston M, Willis LA, Bennet AE. Disability: a model and measurement technique. $\mathrm{Br} J$ Prev Soc Med 1976; 30: 71-8.
${ }^{14}$ Martini CJ, Mc Dowell I. Health status: patient and physical judgements. Health Serv Res 1976; 11: 508-15.

${ }^{15}$ Bebbington AC. Scaling indices of disablement. BrJ Prev Soc Med 1977; 31: 122-6.

${ }^{16}$ Hunt SM, McEwan J. The development of a subjective health status indicator. Sociology of Health and Illness 1980; 2: 231-46.

${ }^{17}$ Everitt B. Cluster analysis. London: Heinemann Educational Books, 1974.

${ }^{18}$ Roland MO, Morris RW. A study of the natural history of back pain: I Development of a reliable and sensitive measure of disability in low back pain. Spine 1983; 8: $\overline{\bar{N}}$ $141-4$.

Appendix (Short (22 item) disability questionnaire)

Because of illness, accident or anything related to your health, do you have difficulty with any of the $\overrightarrow{\vec{\omega}}$ following?

Estimated weights

Yes No Physical Psychosocial

a Walking without help

b Getting outside the house without help

c Crossing the road without help

d Travelling on a bus or train without help

e Getting in and out of bed or chair without help

f Dressing or undressing without help

g Kneeling or bending without help

$\mathrm{h}$ Going up or down stairs without help

i Having a bath or all over wash without help

j Holding or gripping (for example a comb or pen) without help

$\mathrm{k}$ Getting to and using the toilet without help

1 Eating or drinking without help

Because of your health, do you have...

m Difficulty seeing newspaper print even with glasses

$\mathrm{n}$ Difficulty recognising people across the road even with glasses

o Difficulty in hearing a conversation even with a hearing aid

p Difficulty speaking

1
1
1
1
1
1
1
1
1
1
1
1

2
2
2
2
2
2
2
2
2
2
2
2

$0 \cdot 97$

$5 \cdot 38$

$1 \cdot 88$

$3 \cdot 40$

$4 \cdot 66$

$2 \cdot 28$

$2 \cdot 43$

$4 \cdot 52$

$3 \cdot 16$

$2 \cdot 58$

$-0.39$

$2 \cdot 11$

$0 \cdot 18$

$1 \cdot 06$

$1 \cdot 24$

$2 \cdot 38$

$3 \cdot 57$

$0 \cdot 66$

$8 \cdot 44$

Because of your health, do you have difficulty ...

q Preparing or cooking a hot meal without help

$r$ Doing housework without help

s Visiting family or friends without help

$t$ Doing any of your hobbies or spare time activities

u Doing paid work of any kind (if under 65)

$v$ Doing paid work of your choice (if under 65) 